\title{
Okihiro syndrome
}

INSERM

\section{Source}

INSERM. (1999). Orphanet: an online rare disease and orphan drug data base. Okihiro syndrome. ORPHA:93293

Okihiro syndrome is a syndrome of multiple congenital anomalies and is characterized by ocular manifestations (uni- or bilateral Duane anomaly ( $95 \%$ of cases), cong enital optic nerve hypoplasia or optic disc coloboma), bilateral deafness and radial ray malformation that can include thenar hypoplasia and/or hypoplasia or aplasia of the thumbs; hypoplasia or aplasia of the radii; shortening and radial deviation of the forearms; triphalangeal thumbs; and duplication of the thumb (preaxial polydactyly).T he phenotype overlaps with other SALL4 related disorders including acro-renal-ocular syndrome and Holt-Oram syndrome (see these terms). Transmission is autosomal dominant. 